\title{
Improving detection of acoustic sources by coiling fiber optic cable (Erratum)
}

Danielle Peterson, Aaron Meyer, Kyle Dunn, Sergey Vecherin, Dan Glaser, et al.

Danielle Peterson, Aaron Meyer, Kyle Dunn, Sergey Vecherin, Dan Glaser, Dan Costley, Allan Wheeler, Bonnie Jones, Eric Dunn, Mark Moran, "Improving detection of acoustic sources by coiling fiber optic cable (Erratum)," Proc. SPIE 11418, Detection and Sensing of Mines, Explosive Objects, and Obscured Targets XXV, 114180K (8 June 2020); doi: 10.1117/12.2575095 


\title{
Improving detection of acoustic sources by coiling fiber optic cable
}

\author{
Danielle Peterson, ${ }^{1}$ Aaron Meyer, ${ }^{1}$ Kyle Dunn, ${ }^{1}$ Sergey Vecherin, ${ }^{1}$ Dan Glaser, ${ }^{1}$ Dan Costley, ${ }^{1}$ Allan
}

Wheeler, ${ }^{1}$ Bonnie Jones, ${ }^{1}$ Eric Dunn, ${ }^{1}$ Mark Moran ${ }^{1}$

${ }^{1}$ U.S. Army Corps of Engineers, Engineering Research and Development Ctr. (United States)

Proceedings Volume 11418, Detection and Sensing of Mines, Explosive Objects, and Obscured Targets

$\underline{\text { XXV; } 114180 B \text { (2020) https://doi.org/10.1117/12.2559133 }}$

Event: SPIE Defense + Commercial Sensing, 2020, Online Only, California, United States

Online publication date: 24 April 2020

Erratum published: 8 June 2020

This paper, originally published on 24 April 2020, was replaced with a corrected/revised version on 8 June 2020, which includes changes to text and figures $10,11,12,14,15$ and 16 . If you downloaded the original PDF but are unable to access the revision, please contact SPIE Digital Library Customer Service for assistance. 